\title{
Comparação da regulação florestal de projetos de fomento com áreas próprias de empresas florestais
}

\author{
Rafael Rode ${ }^{1 *}$,Helio Garcia Leite ${ }^{2}$, Marcio Leles Romarco de Oliveira ${ }^{3}$, Daniel Henrique Breda Binoti², \\ Carlos Antonio Alvares Soares Ribeiro², Agostinho Lopes de Souza², Marcio Lopes da Silva², Diogo Nepomuceno Cosenza ${ }^{2}$ \\ (1)Universidade Federal do Oeste do Pará, Instituto de Biodiversidade e Florestas, Rua Vera Paz s/n, CEP 68035-110, Santarém, PA, Brasil \\ (2)Universidade Federal de Viçosa, Departamento de Engenharia Florestal, Av. P. H. Rolfs s/n CEP 36570-000, Viçosa, MG, Brasil \\ (3)Universidade Federal dos Vales do Jequitinhonha e Mucuri, Departamento de Engenharia Florestal, Campus JK, Rodovia MGT367, Km 583, CEP 39100-000 \\ Diamantina, MG, Brasil.
}

"Autor correspondente: rafaelrode@gmail.com

Termos para indexação:

Regimes de manejo

Otimização florestal

Propriedades rurais

\section{Index terms:}

Management regimes

Forest optimization

Rural properties
Planejamento florestal

Forest planning

Resumo - Neste estudo, comparou-se o planejamento florestal de projetos de fomento com áreas próprias de empresas florestais. A área total das empresas contempladas no estudo foi de 41.178 ha distribuída em 299 talhões, e a área dos fomentos foi de 2.445 ha, considerando 144 propriedades rurais. O planejamento envolveu programação linear, com objetivo de maximizar o valor anual equivalente (VAE) sob a condição (restrições) de uma estrutura regulada ao final do planejamento. Dois cenários foram avaliados: a) modelo individual - áreas dos fomentados e das empresas em modelos separados, e b) modelo único - áreas dos fomentados e das empresas em um mesmo modelo de programação. A diferença do VAE do modelo individual para o modelo único, mostrou-se desfavorável para os fomentos, pois reduziu seu valor em 14\%. Já nas áreas das empresas, a solução da regulação única mostrou-se favorável com aumento do VAE em aproximadamente 1\%. Verificou-se em um novo cenário do modelo único que, caso a madeira dos fomentos fosse vendida em pé, o VAE global destas áreas aumentaria em $0,9 \%$, sendo, mais interessante aos proprietários.

\section{Forest regulation comparison of forest outgrower schemes projects with own areas of forestry companies}

Histórico do artigo: Recebido em 05/08/2014

Aprovado em 23/03/2015

Publicado em 31/03/2015

doi: $10.4336 / 2015 . p f b .35 .81 .760$

\begin{abstract}
This study compared the forest planning of outgrower schemes projects with own areas of forestry companies' areas. The total area of the companies was 41,178 ha distributed in 299 stands, and the outgrower areas were 2,445 ha distributed in 144 properties. The planning involved linear programming of areas in order to maximize the equivalent annuity (EA), under the condition (constraints) of a regulated structure at the end of planning. Two scenarios were evaluated: a) individual model - areas of outgrower schemes and companies in separate models, and b) single model - areas of outgrower schemes and companies in the same programming model. The EA difference of the individual to the single model was unfavorable to outgrowers, since it reduced its value by $14 \%$. In the companies' areas, the solution of the single regulation was favorable, increasing the EA in approximately $1 \%$. It was also verified in a new scenario of the single model that if the wood of outgrowers were sold by stumpage, the global EA of these areas would increase by $0.9 \%$, thus more attractive to landowners.
\end{abstract}




\section{Introdução}

Como alternativa para se evitar a formação de latifúndios, várias empresas florestais têm adotado o fomento florestal como estratégia para aproximar e aumentar a participação de pequenos proprietários na produção de madeira. Essa estratégia possibilita a oferta de matéria prima à empresa sem que ela assuma os custos envolvidos na aquisição e administração das terras. Além disso, permite o aproveitamento de áreas impróprias para agricultura e favorece a manutenção da população rural no campo (Oliveira, 2003; Canto et al., 2009; Silva et al., 2009).

Uma das principais modalidades de fomento no Brasil é o fomento privado, no qual o contrato entre empresa e produtor é estabelecido com o fornecimento de mudas clonais, insumos, recursos financeiros e assistência técnica por parte da empresa. Em contrapartida, os produtores ficam responsáveis pelo plantio, manutenções, colheita e transporte florestal (Silva et al., 2009). O contrato de fomento determina ainda que o produtor deve vender a maior parte da produção para a empresa, geralmente acima de $90 \%$, na época da colheita. Caso o produtor queira vender para outros mercados, ele estará sujeito à multa por rescisão de contrato (Souza et al., 2009).

Mais recentemente, o termo fomento está sendo utilizado para caracterizar atividades centradas na promoção do desenvolvimento rural, tanto na área florestal como na agropecuária. São projetos e programas de iniciativa pública, privada ou integrada, de estímulo a cultivos diversos (Basso et al., 2012).

As ferramentas de manejo e planejamento da produção florestal estão bem adequadas às empresas de reflorestamento, mediante controle presente e futuro do estoque florestal (Pittman et al., 2007; Beaudoin et al, 2008). Entretanto, considerando que o fomento envolve pequenas e médias propriedades, os modelos de planejamento florestal não são diretamente aplicados aos fomentados, ficando sua época de intervenção determinada pela idade técnica de corte.

Segundo Clutter et al. (1983), o real papel do manejador é gerenciar, de modo inteligente, estruturas florestais não estáveis ou não balanceadas. Problemas de colheita sempre levam à necessidade de maximizar 0 retorno financeiro ou minimizar o custo e atendimento de certas restrições que influenciam nas decisões, levando à necessidade de uso de técnicas de análises mais sofisticadas, como os modelos de pesquisa operacional (PO).

Em empresas de base florestal, a demanda periódica de madeira é a principal restrição nos problemas de programação matemática. O planejamento tem como objetivo principal garantir o abastecimento regular às indústrias, e seu controle pode ser feito via programação linear, por meio de restrições de regulação florestal (Dykstra, 1984; Leuschner, 1990; Buongiorno \& Gilless, 2003).

Neste sentido, a regulação florestal em propriedade de fomento pode ser uma forma de atender às demandas de madeira das empresas, além de garantir receitas regulares ao longo do tempo, tornando o programa de fomento mais atrativo. Para isso, pode ser interessante realizar o planejamento das áreas de fomento do mesmo modo que é feito nas unidades de manejo das empresas, podendo até mesmo incluir essas áreas em um planejamento único para melhor controle da produção.

As pesquisas que envolvem os trabalhos de regulação da produção avançaram no sentido de incluir diferentes fatores nos processos de otimização, permitindo que as técnicas do manejo florestal sejam melhoradas (Rodrigues, 2001; Castro, 2007; Binoti, 2010; Cavalcante, 2011; Monte, 2012). Todavia, até o momento, são poucos os registros de estudos que avaliem o comportamento da produção com inclusão de áreas de fomento nas rotinas de otimização. Esta inclusão também pode ser importante no aspecto social de uma região.

Visando compreender melhor a inclusão das áreas de fomento no planejamento florestal, o objetivo deste trabalho foi comparar a participação do fomento na regulação da produção com áreas próprias de empresas florestais.

\section{Material e métodos}

Este estudo foi realizado com informações obtidas de dois tipos de áreas com plantio de eucalipto localizado no estado de Minas Gerais. O primeiro refere-se a áreas de fomento florestal com contratos de fornecimento de madeira a empresas florestais, enquanto que o segundo tipo, são unidades de manejo florestal de empresas privadas. A área total das empresas contemplada no estudo foi de 41.178 ha distribuída em 299 talhões, enquanto que, para a área de fomento, foi de 2.445 ha 
envolvendo 144 propriedades rurais.

As informações necessárias ao trabalho foram disponibilizadas pelas empresas, sendo: área plantada (ha) por tipo de posse da terra, idade atual dos povoamentos (anos), estimativa da produção $\left(\mathrm{m}^{3} \cdot \mathrm{ha}^{-1}\right)$ por regime de manejo no momento do corte e distância das áreas de fomento em relação aos pátios de estocagem das empresas.

O manejo das áreas é realizado alternando-se entre regimes de alto fuste e talhadia. Na Tabela 1 estão os custos florestais por ano de ocorrência e regime de manejo.

Tabela 1. Descrição dos custos florestais por ano de ocorrência e regimes de manejo utilizados no estudo.

\begin{tabular}{|c|c|c|c|}
\hline Descrição & Ano & Alto fuste $\left(\mathrm{R} \$ \mathrm{ha}^{-1}\right)$ & Talhadia (R\$ ha') \\
\hline Insumos & 0 & $1.939,54$ & $1.550,69$ \\
\hline Assistência técnica & 0 & 130,11 & 130,11 \\
\hline Implantação/condução & 0 & $1.050,00$ & 434,00 \\
\hline \multirow[t]{2}{*}{ Manutenção } & 1 & 240,00 & 240,00 \\
\hline & 2 & 210,00 & 210,00 \\
\hline Custo anual da terra & $0-\mathrm{n}$ & 120,00 & 120,00 \\
\hline Colheita $\left(\mathrm{R} \$ \mathrm{~m}^{-3}\right)^{*}$ & $\mathrm{n}$ & 15,42 & 15,42 \\
\hline Transporte $\left(\mathrm{R} \$ \mathrm{~m}^{-3} \cdot \mathrm{km}^{-1}\right)^{*}$ & $\mathrm{n}$ & 0,23 & 0,23 \\
\hline
\end{tabular}

* Aplicado somente nas áreas de fomento.

Os custos da Tabela 1 também foram considerados para as áreas próprias, com exceção da colheita e transporte que, neste caso, não foram aplicados.

De acordo com o contrato de fomento, os insumos e assistência técnica são subsidiados pelas empresas como incentivo ao programa e, portanto, são custos que incidem sobre as empresas. Os demais custos ficam por conta do proprietário. No entanto, os custos de implantação, condução e manutenções do primeiro e segundo anos, são repassados pelas empresas e descontados dos proprietários por ocasião da colheita.

Nos custos com insumos estão inclusos o fornecimento de formicidas, cupinicidas, herbicidas, fertilizantes e mudas. Para o regime de talhadia os insumos são os mesmos, porém sem a necessidade do fornecimento de mudas.

A distância média das propriedades rurais em relação às empresas foi de $150 \mathrm{~km}$. Todas as estradas foram consideradas de mesma qualidade, com tráfego permitido ao longo de todo o ano.

A produção das áreas foi estimada com ajuste de equações logística, com dados de parcelas permanentes medidas pelas empresas florestais. No regime de talhadia, a produção foi determinada adotando-se $10 \%$ de desconto em relação ao regime de alto fuste.
Para o planejamento das áreas, foi utilizado o modelo tipo I de programação linear (Johnson \& Scheurman, 1977), com objetivo de maximizar o valor anual equivalente - VAE (Silva \& Fontes, 2005), seguido das restrições obrigatórias de área de corte, regulação florestal e demanda anual mínima e máxima (Dykstra, 1984), conforme formulações:

$$
\begin{aligned}
& \text { Função objetivo: } \\
& \operatorname{Max} \mathrm{Z}=\sum_{i=1}^{n} \sum_{j=1}^{m} V A E_{i j} X_{i j} \\
& \text { Restrições: } \\
& \text { Área: } \\
& \sum_{j=1}^{m} X_{i j}=A_{i} \\
& \text { Regulação: } \\
& \sum_{i=1}^{n} \sum_{j=1}^{m} X_{i j k}=\frac{A}{R} \\
& i=1, \ldots, n \\
& \text { Limites de demanda: } \\
& \sum_{i=1}^{n} \sum_{j=1}^{m} V_{i j k} X_{i j} \lessgtr(1 \pm \propto) D_{k} \\
& \begin{array}{c}
k=H-R, \ldots, H-1 \\
\operatorname{Para} H>R
\end{array} \\
& k=1, \ldots, H-1
\end{aligned}
$$

em que: $H=$ horizonte de planejamento; $V A E_{i j}=$ valor anual equivalente por hectare da área $i$, na opção de manejo $j ; X_{i j k}=$ variável de decisão referente ao tamanho da área de manejo $i$ (ha), no período $k ; A_{i}=$ tamanho (ha) da área de manejo $i ; A=$ área total (ha); $R=$ idade regulatória; $V_{i j k}=$ volume por hectare da área $i$, na opção de manejo $j$, do período $k ; D_{k}=$ demanda de volume de madeira no período $k ; a=$ fator para limites de demanda anual. 
As alternativas de manejo do modelo foram geradas considerando opções de corte de cinco a oito anos e o horizonte de planejamento adotado foi de 16 anos (períodos anuais). De posse das alternativas, dois cenários foram criados para comparação: modelo individual $(a)$, e modelo único $(b)$, ambos com restrições de regulação.

O modelo individual (cenário $a$ ) envolveu a otimização das áreas de fomento em separado das áreas próprias. Este cenário serviu ainda de base para comparação do efeito da regulação quando as áreas de fomento são inseridas em um planejamento único com as áreas das empresas (cenário $b$ ).

Para o cálculo do VAE das áreas de fomento, foram considerados no fluxo de caixa os custos de colheita e transporte até os pátios das empresas, como consta em contrato. Para as áreas próprias, considerou-se a madeira em pé, não incidindo, portanto, tais custos para as empresas. Desta forma, o preço atualmente pago pela madeira de fomento foi de $\mathrm{R} \$ 69,37 \mathrm{~m}^{-3}$, enquanto que para a madeira em pé foi determinado a metade deste valor $\left(\mathrm{R} \$ 34,69 \mathrm{~m}^{-3}\right)$.

Na elaboração de um modelo único de planejamento (cenário $b$ ) estas diferenças no fluxo de caixa podem favorecer ou não alguma área em particular (fomento ou própria). Assim, os cenários $a$ e $b$, foram processados por uma segunda vez $(a .2, b .2)$, em que se consideram igualmente a venda da madeira em pé, tanto para as áreas de fomento quanto para as áreas das empresas.

Foi definida a idade de rotação regulatória $(\mathrm{R})$ de sete anos. Assim, para formular este conjunto de restrições, a área de corte anual (ACA) foi calculada por tipo de posse da terra, dividindo-se a área $(\mathrm{A})$ pela idade $\mathrm{R}(\mathrm{ACA}=\mathrm{A}$ / R), conforme Dykstra (1984). A restrição de regulação florestal foi aplicada nos sete últimos períodos, para que as áreas representem todas as classes de idade ao final do planejamento.

A taxa de juros adotada foi de 5\% ao ano. Este valor foi o mesmo adotado pelos bancos credenciados pelo BNDES no programa $\mathrm{ABC}$ para financiamento de projetos de implantação e manejo de florestas comerciais, no ano de 2014.

Por fim, para definir limites de produção periódica no horizonte de planejamento considerado, outro conjunto de restrições foi adicionado ao modelo único, que determina o volume de colheita anual do cenário $b$. Assim, as áreas de fomento mais as áreas das empresas devem atender à demanda anual total, estipulada em $2.124 .000 \mathrm{~m}^{3}$. Para permitir flexibilidade do modelo, variou-se a demanda em $10 \%$ para valores mínimos e máximos $(\mathrm{a}=0,1)$.

\section{Resultados e discussão}

A distribuição das áreas de fomento e das empresas florestais, para a região do estudo, é apresentada na Figura 1. A participação dos fomentados é bem inferior às áreas próprias (apenas $6 \%$ do total). Ainda, as áreas próprias se distribuem em maior amplitude de idade e com algumas unidades de manejo antigas, acima de 10 anos.

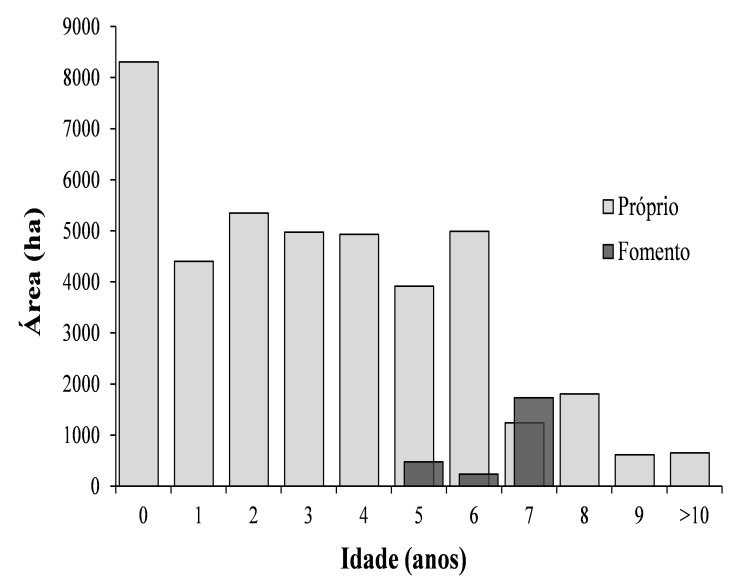

Figura 1. Distribuição das áreas próprias das empresas e de fomento por idade.

Esta diferença na proporção dos tipos de áreas encontradas neste estudo, na região de abrangência das empresas, é comparável à situação nacional. Ao comparar a área de fomento florestal (448,6 mil ha) com o total de plantios florestais no Brasil (6,66 milhões de ha), o fomento representa apenas $6,4 \%$ deste total (Anuário estatístico da ABRAF, 2013). Este número é relativamente pequeno, demonstrando que a maior parte da produção florestal é realizada por plantios comerciais próprios de indústrias (Basso et al., 2012).

Para realizar a regulação das áreas, a área de corte anual (ACA) foi de 349 ha para as áreas de fomento e 5.883 ha para as áreas das empresas.

Os resultados da solução ótima $\left(Z^{*}\right)$ e da produção total dos modelos individuais (cenário $a$ ) e único $(b)$ são apresentados na Tabela 2, para as áreas de fomento e das empresas. 
Tabela 2. Diferenças do valor anual equivalente global $(\mathrm{R} \$)$ e produção total $\left(\mathrm{m}^{3}\right)$ das áreas de fomento e das empresas nos modelos individuais (cenário $a$ ) e único (cenário $b$ ).

\begin{tabular}{|c|c|c|c|c|c|}
\hline \multirow{2}{*}{ Modelo (cenário) } & \multicolumn{5}{|c|}{ Solução (Z*): VAE global (R\$) } \\
\hline & & Fomento & Empresas & & Total \\
\hline Indivic & & $1.200 .781,74$ & $32.272 .580,47$ & & $3.473 .362,21$ \\
\hline Único $(b)$ & & $1.031 .505,09$ & $32.585 .980,84$ & & $3.617 .485,93$ \\
\hline \multirow[t]{2}{*}{ Diferença $(b-a)$} & $\%$ & $-169.276,65$ & (1\%) $313.400,37$ & $(0,4 \%)$ & $144.123,72$ \\
\hline & \multicolumn{5}{|c|}{ Produção total $\left(m^{3}\right)$} \\
\hline Indivi & & $1.720 .860,02$ & $30.939 .970,82$ & & $2.660 .830,84$ \\
\hline Único $(b)$ & & $1.430 .165,51$ & $31.211 .604,85$ & & $2.641 .770,36$ \\
\hline Diferença $(b-a)$ & $(-17 \%$ & $-290.694,51$ & $(0,9 \%) 271.634,03$ & $(-0,1 \%)$ & $-19.060,48$ \\
\hline
\end{tabular}

Fazendo a comparação entre os cenários, o VAE total foi um pouco maior no modelo único $(0,4 \%)$, mas com diferenças maiores por tipo de área. Para as empresas, a regulação pelo modelo único trouxe um leve benefício econômico. A diferença do VAE entre os cenários foi de $1 \%$, o que correspondeu a um ganho de $\mathrm{R} \$ 313.400,37$ no VAE global. No entanto, a regulação florestal em um modelo único (cenário $b$ ) não foi economicamente viável para os fomentos, visto a redução da solução ótima em $14 \%$.

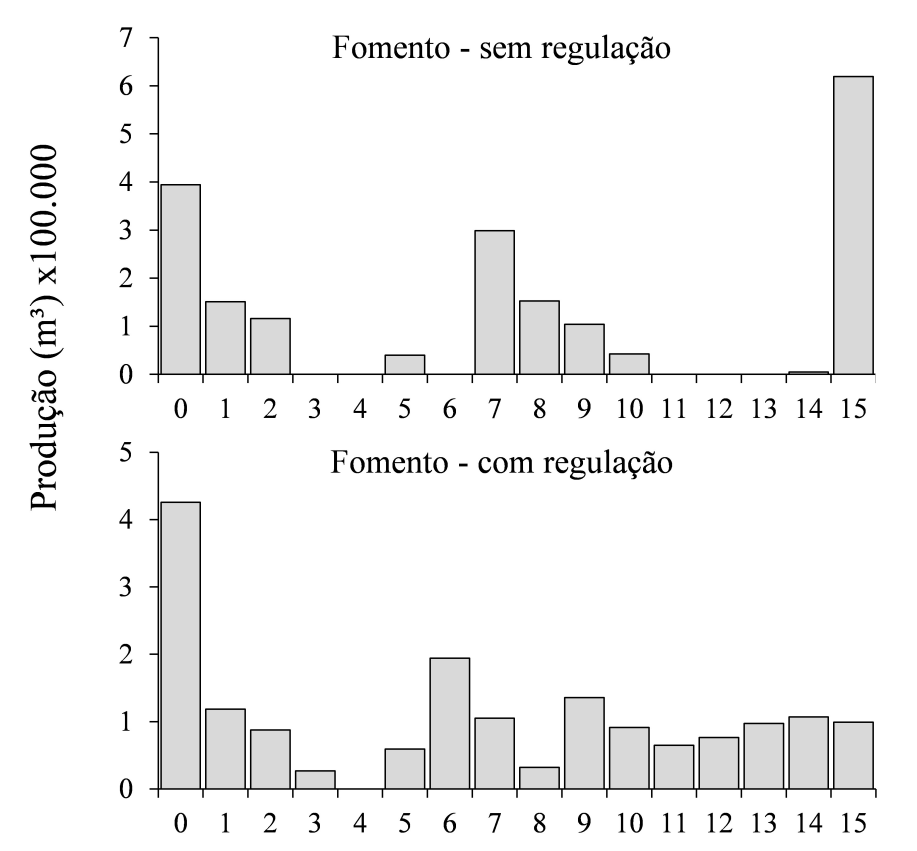

Para a produção florestal o volume $\left(\mathrm{m}^{3}\right)$ também teve maior diferença para as áreas de fomento, sendo $17 \%$ menor do modelo individual para o modelo único. $\mathrm{O}$ efeito da regulação das áreas, para os dois modelos e por período de planejamento pode ser observado na Figura 2. Observa-se o efeito da regulação no final do planejamento, pelo crescimento da produção nos últimos períodos. Assim, ao final do planejamento, as áreas estarão estruturadas em todas as classes de idade.
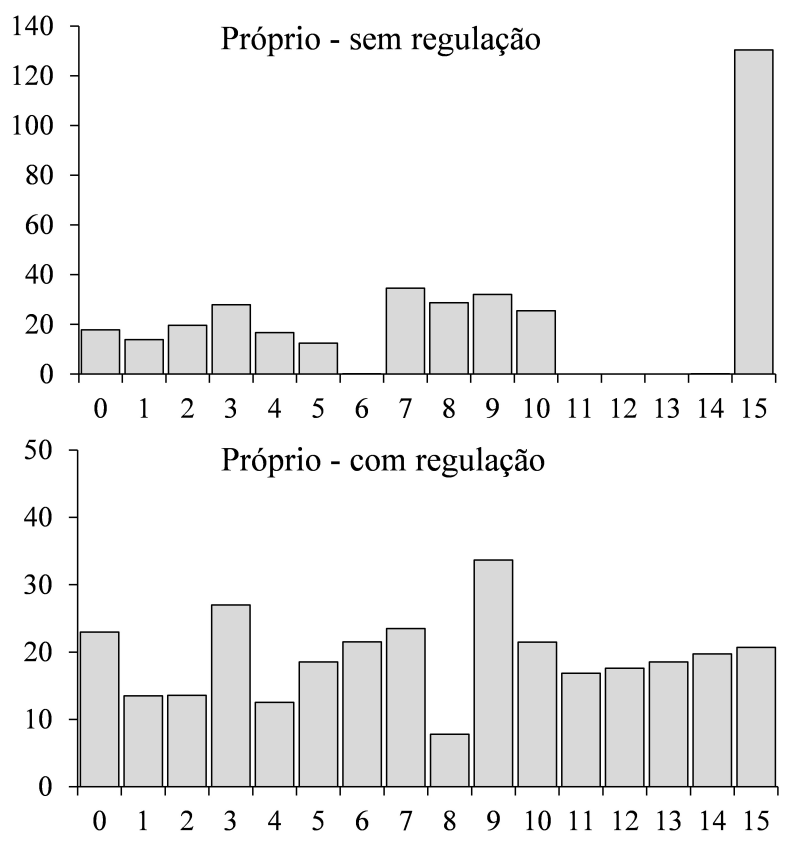

Período de planejamento

Figura 2. Produção total $\left(\mathrm{m}^{3}\right)$ por período de planejamento para as áreas de fomento e própria, sem e com o uso de restrições de regulação. 
Abordagens quantitativas para modelagem de problemas de manejo florestal usam, na maioria das vezes, a programação linear ou a programação por metas. Os modelos desenvolvidos com estas técnicas expressam o impacto das alternativas de manejo sobre os objetivos. A magnitude deste impacto é expressa pelos coeficientes que unem pesos com as variáveis de decisão (Martins \& Borges, 2007; Kurttila \& Pukkala, 2003).

Como esperado, a diferença do VAE entre os cenários se deve à mudança de regime de manejo das unidades para atender às restrições de regulação do modelo. Para as áreas próprias, o aumento da solução ótima do cenário $a$ para o cenário $b$ foi devido à mudança de $7,4 \%$ dos talhões para prescrições de manejo de maior VAE. Já para as áreas de fomento, $83 \%$ das propriedades foram influenciadas pela regulação do cenário de modelo único e assim mudaram para prescrições de menor retorno econômico.

Estas diferenças estão associadas ao coeficiente tecnológico das unidades de área. Enquanto o VAE médio por hectare das áreas de fomento foi de R\$ 421,88 ha-1, para os talhões das empresas foi de $\mathrm{R} \$ 791,34 \mathrm{ha}^{-1}$. Isto quer dizer que as áreas possuem diferentes fluxos de caixa para cálculo do VAE. De fato, para as unidades próprias os custos de colheita e de transporte não foram computados e, apesar do preço da madeira ser a metade do considerado para as áreas de fomento, os coeficientes (VAE) que compõem o modelo foram sempre maiores. Assim, como o objetivo é maximizar lucro, a otimização sempre prioriza maiores coeficientes, deixando a penalização das restrições incidirem mais sobre coeficientes menores.

Dito isto, os cenários foram novamente processados considerando o preço de $\mathrm{R} \$ 34,69 \mathrm{~m}^{-3}$ para venda da madeira em pé e sem custos de colheita e de transporte para ambas as áreas. Os resultados destes novos cenários (a.2 e b.2) estão apresentados na Tabela 3.

Tabela 3. Diferenças do valor anual equivalente global (R\$) das áreas de fomento e das empresas nos modelos individuais (cenário a.2) e único (cenário b.2).

\begin{tabular}{|c|c|c|}
\hline \multirow{2}{*}{$\begin{array}{l}\text { Modelo } \\
\text { (cenário) }\end{array}$} & \multicolumn{2}{|c|}{ Solução (Z*): VAE global (R\$) } \\
\hline & Fomento & Empresas \\
\hline Individual (a.2) & $3.269 .965,00$ & $32.272 .580,47$ \\
\hline Único $(b .2)$ & $3.298 .653,59$ & $32.259 .536,41$ \\
\hline Diferença $(b-a)$ & $(0,9 \%) 28.688,59$ & $(-0,04 \%) \quad-13.044,06$ \\
\hline
\end{tabular}

Observa-se na Tabela 3, que as áreas de fomento foram agora favorecidas pelo modelo único, com aumento de $0,9 \%$ na solução final. Esta mudança favorável foi ocasionada pelo aumento dos coeficientes do VAE, que passaram a ter em média $\mathrm{R} \$ 1.443,63 \mathrm{ha}^{-1}$, sendo superior à média dos coeficientes das áreas de propriedade das empresas.

Considerando o número de áreas que mudaram de alternativa de manejo, mais da metade $(55,6 \%)$ dos fomentos passaram para prescrições de maior VAE. Para as áreas das empresas, a redução do VAE para o cenário único (b.2) foi mínima (-0,04\%), correspondendo a 5,4\% de talhões que mudaram para prescrições de menor retorno econômico.

Dos resultados obtidos até o momento, algumas deduções podem ser feitas. As áreas próprias das empresas podem ser consideradas como projetos florestais independentes, pois não possuem doações de insumos e de mudas como nas áreas de fomento e consideram a venda de madeira em pé. Quando considerados os custos de colheita e de transporte para as áreas de fomento (cenário $b$ ) o VAE médio foi menor em comparação ao das áreas próprias, e maior quando não considerados (cenário b.2). Dessa forma, para o produtor rural é mais vantajoso abrir mão das doações do programa e vender a madeira em pé para as empresas pela metade do preço atualmente praticado, uma vez que o fluxo de caixa das áreas de fomento consideraria custos e receitas comparáveis às áreas próprias e assim seus coeficientes estariam mais equilibrados.

De acordo com Canto et al. (2006), a colheita e transporte florestais são terceirizados na maioria dos contratos de fomento, principalmente pela falta de máquinas e equipamentos, indisponibilidade de tempo, custo elevado e falta de recursos financeiros e de mãode-obra especializada. Silva et al. (2009) apontam o custo de transporte para o produtor como o principal desmotivador para o investimento em plantação florestal para produção de celulose.

Rezende et al. (2006), realizando um estudo econômico de plantios florestais com fomento, concluíram que a venda da madeira em pé se mostrou economicamente viável para qualquer simulação, exigindo o maior subsídio. O custo da madeira colocada no pátio da empresa fomentadora foi altamente influenciado pelo custo de transporte, sendo a viabilidade dos projetos altamente influenciada pelo preço da madeira, portanto, pela distância e pela produtividade. 
A produtividade das áreas também influencia o fluxo de caixa. Nos talhões das empresas, as atividades silviculturais são mais bem realizadas, enquanto que nas áreas de fomento, apesar da assistência técnica oferecida pela empresa, os proprietários podem realizálas de diferentes maneiras, prejudicando a qualidade do povoamento. Mesmo em locais de melhor capacidade produtiva, a produtividade esperada pode não ser alcançada.

Apesar de os produtores terem confiança na empresa fomentadora quanto ao nível de assistência técnica oferecida para condução do plantio (Silva et al., 2009), sua disponibilidade é deficiente (Cordeiro et al., 2009). É esperado que o ciclo de produção em áreas de fomento seja pouco desenvolvido tecnologicamente e a mão-deobra utilizada é, em sua maioria, familiar, sendo que os equipamentos utilizados são os mesmos aplicados em outras atividades da propriedade, com algumas

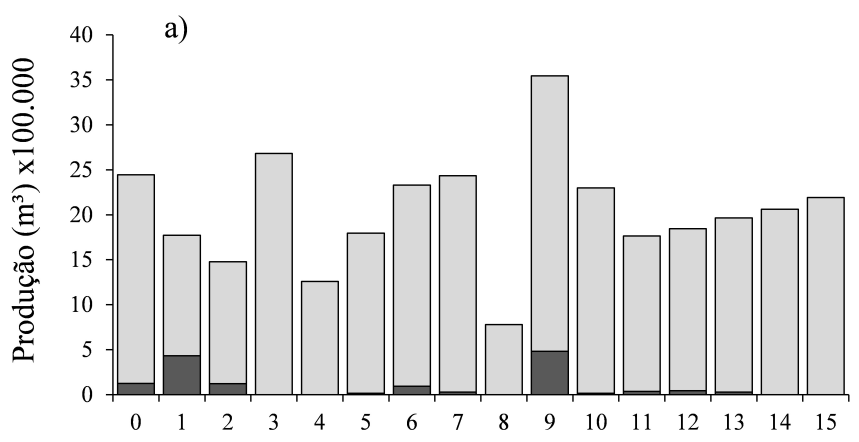

adaptações (Canto et al., 2006; Siqueira et al., 2004).

Ainda na Tabela 2, observa-se que para o cenário inicial de modelo único $(b)$ as áreas de fomento podem ser favorecidas caso ocorra aumento no preço da madeira, melhores incentivos do programa pelas empresas e por órgãos públicos, melhoria das práticas silviculturais, etc.

Outra questão quanto ao modelo único do cenário $b$, é se este poderia ser aplicado sem prejudicar as áreas de fomento. Neste caso, é possível adicionar às restrições deste modelo o conjunto de restrições de regulação do modelo individual do cenário $a$, para que ao final do período o inventário das áreas de fomento esteja com idades de 1 a $\mathrm{R}$ anos.

Esta situação foi testada neste estudo, cujos resultados estão apresentados na Figura 3, em que: a) representa a produção para o período de planejamento do modelo único e b) o modelo único mais as restrições de regulação das áreas de fomento.

b)

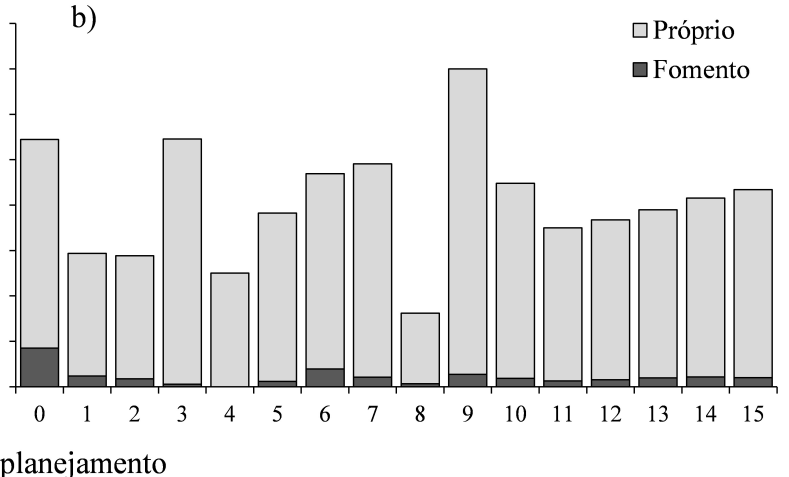

Figura 3. Produção total $\left(\mathrm{m}^{3}\right)$ por período de planejamento para as áreas próprias e de fomento, com restrições de regulação; a) modelo único; b) modelo único com restrições de regulação para o total e áreas de fomento.

A inclusão destas restrições no modelo para manter as áreas de fomento em uma estrutura regulada com as áreas das empresas retorna aos mesmos resultados do cenário individual (cenário $a$ ), independentemente do tipo de área. Assim, a Figura 3b representa a mesma situação da Figura 2 para a regulação das áreas.

Regular a produção de uma floresta significa que após um período de transição, ou horizonte de planejamento, obtém-se uma produção sustentável (Campos \& Leite, 2013; Dykstra, 1984). Pelos resultados apresentados, após o planejamento as áreas próprias e de fomento deverão desenvolver um cronograma de atividades onde a colheita é igual ao crescimento. No entanto, na prática, as condições meteorológicas, distribuições irregulares de classes de idade, danos nos produtos causados pela colheita e outros fatores, contribuem para variações nas colheitas em relação ao crescimento da floresta (Bettinger et al., 2009).

Ainda nesta situação, pode ser desejado que o fornecimento de madeira para a indústria não tenha muita variação na produção durante os períodos de planejamento. Logo, o modelo único, mantendo a estrutura regulada das áreas de fomento, pode ser mais útil no planejamento global, com a inclusão das restrições de demanda.

Na Figura 4 estão apresentados os resultados para o modelo único, incluindo restrições de produção variando em $10 \%$ da demanda industrial $\left(2.124 .000 \mathrm{~m}^{3}\right.$. ano $\left.{ }^{-1}\right)$. Esta nova situação procura equilibrar o planejamento das áreas sem trazer desvantagens a uma das partes. 
Os resultados do VAE das áreas são comparáveis aos apresentados na Tabela 2, com pouca diferença para menos, de $0,3 \%$ e $0,4 \%$ para as áreas de fomento e das empresas, respectivamente.

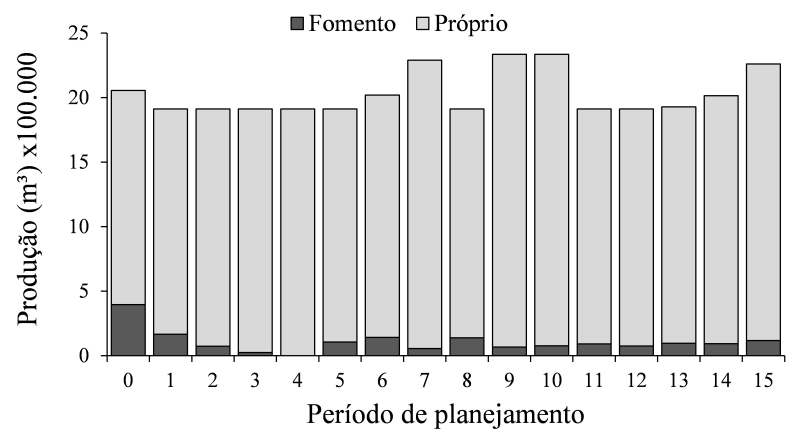

Figura 4. Modelo de programação único com restrições de regulação da produção e regulação das áreas de fomento.

De acordo com Silva et al. (2009), o planejamento em longo prazo das empresas com áreas de fomento deve garantir maior estabilidade na oferta de madeira, com perspectivas de crescimento para região. Isto sugere a renovação constante dos contratos, uma vez que estarão previstos vários ciclos de corte. Em geral, contratos de fomento possuem duração de uma rotação, com menor aceite de renovação por parte dos proprietários. Oliveira et al. (2006) apontam que produtores rurais, em sua maioria, entram e saem do programa de fomento florestal pela via contratual, porém não abandonam a atividade de silvicultura.

Isto se apresenta como principal desafio para as empresas, que devem sugerir um replanejamento das estratégias, reduzir riscos de quebra de contratos e melhorar sua relação com os proprietários rurais. Mesmo que haja concordância por parte dos fomentados, o planejamento de modelo único deve procurar melhorar o nível de aceitação destes contratos e, no mínimo, garantir a renda esperada pelos produtores antes de sua elaboração.

\section{Conclusões}

Ao fim do planejamento foi possível obter uma estrutura regulada das florestas com áreas de fomento e próprias das empresas florestais.

Em comparação com o modelo único para regulação florestal, no qual o planejamento das áreas de fomento é feito juntamente como planejamento das áreas das empresas florestais, os resultados foram desfavoráveis para o proprietário rural fomentado, principalmente devido aos custos de colheita e transporte.

A venda da madeira em pé pela metade do preço atual mostrou-se mais favorável aos fomentos, também para o modelo único de planejamento, sem prejuízos aos proprietários.

O planejamento único pode ser feito pelas empresas florestais sem prejudicar as áreas de fomento, desde que o conjunto de restrições de regulação seja separado por tipo de área. Assim, outras restrições, como o limite de demanda industrial podem ser inseridas sem afetar consideravelmente a solução para as áreas de fomento.

Em outras situações, é provável que o modelo único venha favorecer os proprietários rurais caso o objetivo seja priorizar a renda dos proprietários. Isto pode ser alcançado quando os coeficientes do modelo das áreas de fomento forem maiores que nas áreas próprias, por meio do aumento no preço da madeira, melhores incentivos do programa pelas empresas ou por órgãos públicos e melhoria das práticas silviculturais.

\section{Referências}

ANUÁRIO estatístico ABRAF 2013: ano base 2012. Brasília, DF, 2013.

BASSO, V. M.; JACOVINE, L. A. G.; GRIFFITH, J. J.; NARDELLI, A.; ALVES, R. R.; SOUZA, A. L. Programas de fomento rural no Brasil. Pesquisa Florestal Brasileira, Colombo, v. 32, n. 71, p. 321-334, 2012. DOI: 10.4336/2012.pfb.32.71.321

BEAUDOIN, D.; FRAYRET, J. M.; LEBEL, L. Hierarchical forest management with anticipation: an application to tactical-operational planning integration. Canadian Journal of Forest Research, Ottawa, v. 38, p. 2198-2211, 2008.

BETTINGER, P.; BOSTON, K.; SIRY, J. P.; GREBNER, D. L. Forest management and planning. New York: Elsevier, 2009. 331 p.

BINOTI, D. B. Estratégias de regulação de florestas equiâneas com vistas ao manejo da paisagem. 2010. 145 f. Dissertação (Mestrado em Ciência Florestal) - Universidade Federal de Viçosa, Viçosa, MG.

BUONGIORNO, J.; GILLESS, J. K. Decision methods for forest resource and management. California: Academic Press, 2003. $439 \mathrm{p}$.

CAMPOS, J. C. C.; LEITE, H. G. Mensuração florestal: perguntas e respostas. 4 ed. Viçosa, MG: Ed da UFV. 2013. 605 p.

CANTO, J. L.; MACHADO, C. C.; GONTIJO, F. M.; JACOVINE, L. A. G. Colheita e transporte florestal em propriedades rurais fomentadas no estado do Espírito Santo. Revista Árvore, Viçosa, MG, v. 30, n. 6, p. 989-998, 2006.

CANTO, J. L.; GONTIJO COELHO, F. M.; NOCE, R.; MACHADO, C. C.; REZENDE, J. L. P.; MENDES, L. M.; OLIVEIRA, J. M. 
Aspectos sociais do fomento florestal no estado do Espírito Santo. Cerne, Lavras, v. 15, n. 2, p. 123-132, 2009.

CASTRO, R. R. Regulação de florestas equiâneas incluindo restrições de adjacência. 2007. 64 f. Dissertação (Mestrado em Ciência Florestal) - Universidade Federal de Viçosa, Viçosa, MG.

CAVALCANTE, R. B. L. Planejamento de povoamentos de eucalipto com condicionantes hidrológicos: um estudo de caso em Eldorado do Sul-RS. 2011. 102 f. Dissertação (Mestrado em Recursos Hídricos e Saneamento Ambiental) - Universidade Federal do Rio Grande do Sul, Porto Alegre.

CLUTTER, J. L.; FORSTON, J. C.; PIENAAR, L. V.; BRISTER, G. H.; BAILEY, R. L. Timber management: a quantitative approach. 3. ed. New York: Jonh Willey, 1983. 333 p.

CORDEIRO, S. A.; SILVA, M. L.; JACOVINE, L. A. G.; VALVERDE, S. R.; ROCHA, J. L.; SOARES, N. S. Desempenho do fomento do órgão florestal em Minas Gerais. Cerne, Lavras, v. 15, n. 3, p. 273-281, 2009.

DYKSTRA, D. P. Mathematical programming for natural resource management. New York: McGraw-Hill, 1984. 318 p.

JOHNSON, K. N.; SCHEURMAN, H. L. Techniques for prescribing optimal timber harvest and investment under different objectives: discussion and synthesis. Forest Science. Monograph, n. 18, p. 1-31, 1977.

KURTTILA, M.; PUKKALA, T. Combining holding-level economic goals with spatial landscape-level goals in the planning of multiple ownership forestry. Landscape Ecology, Dordrecht, v. 18, n. 5, p. 529-541, 2003.

LEUSCHNER, W. A. Forest regulation, harvest scheduling, and planning techniques. New York: John Wiley, 1990. 281 p.

MARTINS, H.; BORGES, J. G. Addressing collaborative planning methods and tools in forest management. Forest Ecology and Management, Amsterdam, v. 248, p. 107-118, 2007.

MONTE, M. Inclusão de critérios sociais na modelagem matemática do planejamento florestal. 2012. $74 \mathrm{f}$. Tese (Doutorado em Ciência Florestal) - Universidade Federal de Viçosa, Viçosa, MG.

OLIVEIRA, P. R. S. Diagnóstico e indicadores de sustentabilidade em fomento florestal no Estado do Espírito Santo. 2003. $127 \mathrm{f}$. Dissertação (Mestrado em Ciência Florestal) Universidade Federal de Viçosa, Viçosa, MG.
OLIVEIRA, P. R. S.; VALVERDE, S. R.; COELHO, F. M. G. Aspectos de relevância econômica no fomento florestal a partir da percepção dos produtores rurais envolvidos. Revista Árvore, Viçosa, MG, v. 30, n. 4, p. 593-601, 2006.

PITTMAN, S. D., BARE, B. B., BRIGGS, D. G. Herarchical production planning in forestry using price-directed decomposition. Canadian Journal of Forest Research, Ottawa, v. 37, p. 2010-2021, 2007.

REZENDE, J. L. P.; PADUA, C. T. J.; OLIVEIRA, A. D.; SCOLFORO, J. R. S. Análise econômica de fomento florestal com eucalipto no estado de Minas Gerais. Cerne, Lavras, v. 12, n. 3, p. 221-231, 2006.

RODRIGUES, F. L. Metaheurística e sistema de suporte à decisão no gerenciamento de recursos florestais. 2001. $253 \mathrm{f}$. Tese (Doutorado em Ciência Florestal) - Universidade Federal de Viçosa, Viçosa, MG.

SILVA, M. L.; FONTES, A. A. Discussão sobre os critérios de avaliação econômica: Valor Presente Líquido (VPL), Valor Anual Equivalente (VAE) e Valor Esperado da Terra (VET). Revista Árvore, Viçosa, MG, v. 29, n. 6, p. 931-936, 2005.

SILVA, F. L.; GRIFFITH, J. J.; JACOVINE, L. A.; VALADARES, J. H.; FERNANDES, M. A. S.; SILVA, E. C. G. Estudo da relação de confiança em programas de fomento florestal de indústria de celulose na visão dos produtores rurais. Revista Árvore, Viçosa, MG, v. 33, n. 4, p. 723-732, 2009.

SIQUEIRA, J. D. P.; LISBOA, R. S.; FERREIRA, A. M.; SOUZA, M. F. R.; ARAÚJO, E.; LISBÃO-JÚNIOR, L.; SIQUEIRA, M. M. Estudo ambiental para os programas de fomento florestal da Aracruz Celulose S.A. e extensão florestal do Governo do Estado do Espírito Santo. Floresta, ed. especial, p. 3-67, 2004.

SOUZA, U. R.; SILVA, F. L.; GRIFFITH, J. J.; LIMA, J. E.; QUINTELA, M. C. A.; COSTA, E. C. V. Determinantes de novos contratos de fomento florestal na mesoregião do Vale do Rio Doce, Minas Gerais. Revista Árvore, Viçosa, MG, v. 33, n. 2, p. 377-386, 2009. 
